\title{
Engineering of Osteoblasts for Bone Replacement: How to Test for Acquisition and Maintenance of a Proper Phenotype
}

\section{Jan Oxholm Gordeladze*}

Institute of Basic Medical Science, Department of Biochemistry, University of Oslo, Norway, Europe

Osteoblasts may be engineered from stem cells derived from various sources, like blood marrow (mesenchymal stem cells = MSCs) or adipose tissue (adipose derived stem cells = ADSCs), but also from embryonic stem cells (ESCs) and induced pluripotent stem cells (iPSCs). Such osteoblasts are normally characterized using various criteria selected from parameters, like osteoblast specific marker genes (e.g. transcription factors $=\mathrm{TFs}$, components related to BMP- and Wnt-mediated signaling), matrix structural proteins (e.g. collagens, osteopontin, osteomodulin), secreted enzymes (e.g. alkaline phosphatase, metalloproteinases), and other specific markers like osteocalcin [1].

Bone tissue harbors many functional cell types like osteoblasts, osteocytes and osteoclasts, and bone modeling and remodeling depends on the osteoblast, to acquire a set of defined characteristics throughout their life span in a remodeling cycle (including the synthesis and secretion of the osteoclast activator RANK-L and the decoy receptor for $\mathrm{OPG}=$ osteoprotegerin). For the remodeling cycle to take place, it is also vital that deposited growth factors (e.g. transforming growth factor $=$ TGF) are released by resorbing osteoclasts, to attract osteoblast to form and mineralize matrix proteins in the resorption pits. Furthermore, a well-orchestrated interplay with the immune system and the nervous system is necessary for proper bone development and maintenance. Functional bone is also dependent upon a continuous supply of oxygen and nutrients; hence vascularization of engineered bone is vital. Lastly, but also important, is the concept of mechanostimulation of bone modeling and remodeling, to ensure proper long term bone health [2].

All these aspects are indigenously considered by the living bone, however, when engineered osteoblasts or osteoblasts developed in scaffolds are used for bone replacements, there is no guarantee that proper 3D bone development and bone turnover will be achieved. Furthermore, mechano-stimulation may be lost or introduced too late, and the 3D structure of the engineered bone does not allow proper invasion of adjacent cell from the host. The injury, which have destroyed bone tissue in the host, may be hard to "eradicate" (e.g. cancer, chronic inflammation), thus placing a stronger demand for phenotype "resilience" on the engineered osteoblasts [1,3,4].

The big question is therefore: what would be a minimal array of growth conditions and manipulations to perform, in order to bring the engineered osteoblasts into a state where they, when introduced into a defined site of injury, will develop into a proper, stable and selfrenewing bone tissue? Despite the complexity of the subject proposed screening system, it may be wise to follow a procedure, which may be described briefly as follows:

1. Check different sources of stem cells for surface antigens (they should be positive for CD44, CD49, CD29, CD90, CD105 and CD106, and negative for STRO-1, CD34, CD45, and CD117), and highly positive for bone mineralization (Alizarin red S) coloration in $2 \mathrm{D}$ cultures.

2. Use promising stem cell sources and perform permutations of incubation condition (over a period of some 4-6 weeks), focusing on elements including: growth factors (TGFs/BMPs), manipulation (through vectors with inducible promoters) of genes like transcription factors, osteoblast signature microRNAs, transcription factors and histone deacetylases (HDACs and Sirtuins), and various types of scaffolds, mechano-stimulation (in vitro sheer forces and compression, or vibration platforms in small animal model system) [1,3,5-9].

3. Analyze gene expression profiles as you go along, focusing on a custom made, minimal size transcriptome (consisting of approximately 400-500 genes, which has yet to be determined), encompassing genes, including as many as possible of the two GO-terms (gene ontology terms): skeletogenesis (181 genes) and angiogenesis (172 genes), presented in the Panther algorithm (http://www.pantherdb.org/tools/compareToRefList.jsp) (or using a similar set of transcripts).

4. Apply the Mir@nt@n algorithm (http://maia.uni.lu/mironton. php) [10] to emulate an integrated, hierarchical, regulatory loop system, encompassing microRNAs, HDACs and transcripts from the custom made osteoblast transcriptome.

5. Finally, if $\mathrm{p}$-values for the GO-terms (skeletogenesis and angiogenesis) yield significantly higher probabilities for compliance with both phenotypes, upon a specific permutation in stem cell differentiation (see \#2 above), then one might conclude that, the in vitro differentiation scheme yields useful engineered osteoblasts to be tested in in vitro model systems.

6. Use animal model systems with induced bone lesions to test the engineered osteoblasts, and analyze for bone quality (micro CT and acquired bone strength). If deemed necessary, also check for ingrowth of vessels and the presence of attracted osteoclasts (Q-PCR of osteoclast-specific transcripts) from adjacent bone tissue $[2,4]$.

In summary, this procedure of engineering osteoblasts offers a way of assessing, whether in vivo bone replacement (or de novo formed 3D bone tissue) in fact will be functional and resilient to destruction over time, and thus, possibly represents a guide to a more successful healing of bone lesions, through osteoblast engineering from stem cells.

*Corresponding author: Jan Oxholm Gordeladze, Institute of Basic Medica Science, Department of Biochemistry, University of Oslo, Norway, Europe, Tel: +47-917-01076; Fax: +47-22-851058; E-mail: j.o.gordeladze@medisin.uio.no

Received September 27, 2012; Accepted September 28, 2012; Published October 01, 2012

Citation: Gordeladze JO (2012) Engineering of Osteoblasts for Bone Replacement: How to Test for Acquisition and Maintenance of a Proper Phenotype. J Tissue Sci Eng 3:e114. doi:10.4172/2157-7552.1000e114

Copyright: ( 2012 Gordeladze JO. This is an open-access article distributed under the terms of the Creative Commons Attribution License, which permits unrestricted use, distribution, and reproduction in any medium, provided the original author and source are credited. 
Citation: Gordeladze JO (2012) Engineering of Osteoblasts for Bone Replacement: How to Test for Acquisition and Maintenance of a Proper Phenotype. J Tissue Sci Eng 3:e114. doi:10.4172/2157-7552.1000e114

\section{References}

1. Gordeladze JO, Djouad F, Brondello JM, Noel D, Duroux-Richard I, et al. (2009) Concerted stimuli regulating osteo-chondral differentiation from stem cells: phenotype acquisition regulated by microRNAs. Acta Pharmacol Sin 30 : 1369-1384.

2. Gordeladze JO, Reseland JE, Duroux-Richard I, Apparailly F, Jorgensen C (2009) From stem cells to bone: phenotype acquisition, stabilization, and tissue engineering in animal models. ILAR J 51: 42-61.

3. Gordeladze JO, Reseland JE, Karlsen TA, Jakobsen RB, Engebretsen L, et al. (2011) Bone and Cartilage from Stem Cells: Growth Optimalization and Stabilization of Cell Phenotypes. Regenerative Medicine and Tissue Engineering - Cells and Biomaterials

4. Gordeladze JO, Reseland JE, Karlsen TA, Jakobsen RB, Lyngstadaas SP, et al. (2012) Engineering inflammation-resistant osteochondral cells. Regenerative Medicine and Tissue Engineering, InTech Publishing Company.
5. Ozcivici E, Luu BK, Adler B, Qin YX, Rubin J, et al. (2010) Mechanical signals as anabolic agents in bone. Nat Rev Rheumatol 6: 50-59.

6. Venugopal J, Prabhakaran MP, Zhang Y, Low S, Choon AT, et al. (2010) Biomimetic hydroxyapatite-containing composite nanofibrous substrates for bone tissue engineering. Philos Transact A Math Phys Eng Sci 368:2065-2081.

7. Janicki $P$, Schmidmaier $G$ (2011) What should be the characteristics of the ideal bone graft substitute? Combining scaffolds with growth factors and/or stem cells. Injury 42: S77-S81.

8. Yun YR, Jang JH, Jeon E, Kang W, Lee S, et al. (2012) Administration of growth factors for bone regeneration. Regen Med 7: 369-385.

9. McGee-Lawrence ME, Westendorf JJ (2011) Histone deacetylases in skeletal development and bone mass maintenance. Gene 474: 1-11.

10. Le Béchec A, Portales-Casamar E, Vetter G, Moes M, Zindy PJ, et al. (2011) MIR@NT@N: a framework integrating transcription factors, microRNAs and their targets to identify sub-network motifs in a meta-regulation network model. BMC Bioinformatics 12: 67 . 